Full Paper

\title{
Determination of Iodide and Idoxuridine at a Glutaraldehyde-Cross-Linked Poly-L-Lysine Modified Glassy Carbon Electrode
}

\author{
Francisco C. Pereira, ${ }^{\mathrm{a}}$ Arnold G. Fogg, ${ }^{\mathrm{b}}$ Paolo Ugo, ${ }^{\mathrm{c}}$ Erwing. P. Bergamo, ${ }^{\mathrm{a}}$ Nelson.R. Stradiotto, ${ }^{\mathrm{a}}$ Maria Valnice B. \\ Zanoni $^{* a}$ \\ a Departamento de Química Analítica, Instituto de Química - Universidade Estadual Paulista, Caixa Postal 355, \\ 14801-970, Araraquara-S.P, Brazil \\ *e-mail: boldrinv@iq.unesp.br \\ b Luton Institute, University of Luton, Luton, LU1 5DU, UK and Loughborough University, Loughborough, \\ Leicestershire LE11 3TU, UK \\ c Dipartimento Chimica Fisica, S. Marta 2137, Universitá Ca'Foscari di Venezia, Venice, Italy
}

Received: November 9, 2004

Accepted: January 20, 2005

\begin{abstract}
The detection limit (about $0.017 \mu \mathrm{g} \mathrm{mL}{ }^{-1}$ ) for voltammetric determination of iodide (peak at $+0.87 \mathrm{Vvs}$. $\mathrm{Ag} / \mathrm{AgCl}$ at $\mathrm{pH} 2$ ) at a glutaraldehyde-cross-linked poly-L-lysine modified glassy carbon electrode involving oxidation to iodine was found to be several orders of magnitude lower than that for the voltammetric determination on a bare glassy carbon electrode. This method was applied successfully to the determination of iodide in two medicinal formulations. Idoxuridine was determined indirectly at the same electrode by accumulating it first at $-0.8 \mathrm{~V}$ vs. $\mathrm{Ag} / \mathrm{AgCl}$. At this potential the $\mathrm{C}-\mathrm{I}$ bond in the adsorbed idoxuridine is reduced giving iodide, which is then determined at the modified electrode. The method was successfully applied to the determination of idoxuridine in a urine sample.
\end{abstract}

Keywords: Glutaraldehyde-cross-linked poly-L-lysine modified glassy carbon electrode, Iodide determination, Idoxuridine determination, Modified electrode

\section{Introduction}

Idoxuridine (IDU), 5-iodo-2'-deoxyuridine, was the first antiviral drug developed for the topical treatment of herpes simplex disease $[1,2]$. It is a halogenated nucleoside, whose chemical structure (Fig. 1) has the capability of interfering in the genetic makeup of the herpes virus by the substitution of thymidine in this structure. This leads to the generation of modified DNA resulting in impotent viral replication $[2,3]$. Several studies have suggested the extension of the use of IDU to the treatment of the cancer [4-6]. However, the pharmacokinetics of IDU allows limited use in therapy owing to the rapid dehalogenation and further metabolism of IDU [6]. Among various strategies to improve its efficiency the preparation of macromolecular pro-drugs

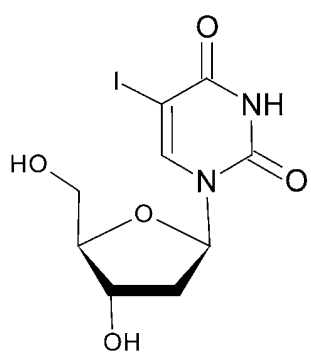

Fig. 1. Chemical structure of idoxuridine. has been investigated, in which the IDU is covalently bonded to low molecular weight, water soluble, biodegradable polymers $[7,8]$.

The official method for the assay of idoxuridine involves the classical non-aqueous titration with sodium methoxide solution in a suitable solvent as titrant [9]. A method involving a complex chromatographic extraction followed by UV spectrophotometric measurement is also described in the literature [10]. Several chromatographic methods for the bioanalysis of idoxuridine and other antiviral agents are also described [11]. Amankwa et al. [12] investigated the electrochemical reduction of idoxuridine and showed that the compound exhibited well- defined dc and differential pulse polarographic waves and peaks at around -0.97 vs. SCE. The electroreduction mechanism on mercury was shown to involve a two- electron transfer and cleavage of the carbon-halogen bond. A differential pulse polarographic assay method was developed for the determination of idoxuridine in ophthalmic solutions after prior extraction, but the calibration graph was only indicated to be linear over the concentration range $1 \times 10^{-4} \mathrm{~mol} \mathrm{~L}^{-1}$ to $5 \times 10^{-4} \mathrm{~mol}$ $\mathrm{L}^{-1}$.

The modification of glassy carbon, screen printed carbon, platinum and gold electrodes with films of poly-L-lysine (PLL) have been investigated by several authors [13-19]. PLL is a synthetic polyamino acid with $\mathrm{NH}_{2}$ groups in the side chain, which are protonated up to $\mathrm{pH} 10.5$. It can be 
used to prepare electrodes modified with thin films of PLL, which have ion-exchange properties, and this has provided a new approach in electroanalytical chemistry. The most important properties observed are those of facilitating electron transfer, decreasing overpotentials significantly, and pre-concentrating anionic compounds. Recently the present authors have shown that the light crosslinking of PLL by means of glutaraldehyde $(97.5 \%$ PLL $/ 2.5 \%(\mathrm{~m} / \mathrm{v})$ produces stronger adhesion to the electrode surface, without affecting significantly the high anion exchange capacity of the PLL [20].

Because of the known anion exchange properties of PLL films, their ability to accumulate iodide was tested and confirmed in the present study. Iodine is an essential trace element for the well being of the human organism because iodine-containing hormones, which play a very important role in mental development, growth and basic metabolism, are produced in the thyroid gland. Because of this biological role of iodine a number of analytical methods are employed and have been suggested for the routine determination of iodide in pharmaceutical products [21-25]. Many of these are electrochemical methods, which are usually based on the oxidation of iodide to molecular iodine, but sometimes involve further oxidation to $\mathrm{IO}^{-}$or $\mathrm{IO}_{3}^{-}$at more positive potentials. These methods include stripping voltammetry with potentiostatic or open circuit accumulation [26-28], the use of chemically modified electrodes with the formation of ion pairs $[29,30]$, the use of complexing ligands [31] and of ion exchangers $[32,33]$.

In the present work the feasibility of determining both iodide and IDU at PLL/glut modified glassy carbon electrodes was investigated.

\section{Experimental}

\subsection{Apparatus and Reagents}

An EG\&G (PARC) 362 potentiostat controlled by a compatible microcomputer with AVOLM software was used for carrying out the cyclic voltammetric experiments. A three electrode system consisting of an EG\&G (PARC) Ag/ $\mathrm{AgCl}\left(3 \mathrm{~mol} \mathrm{~L}^{-1}\right)$ reference electrode, a platinum wire auxiliary electrode and a glassy carbon electrode as working electrode were used. Unless specified otherwise, all potentials reported here are referred to this $\mathrm{Ag} / \mathrm{AgCl}$ electrode. The $\mathrm{pH}$ measurements were carried out using a Micronal $\mathrm{pH}$ meter B222 model with a Micronal combined pH/reference electrode.

Suprapur grade reagents supplied by Merck and demineralized water from a Milli-Q system (Milli-pore) were used in the preparation of all solutions. The studies were carried out in Britton-Robinson buffer $\left(0.4 \mathrm{~mol} \mathrm{~L}^{-1}\right.$ in each of acetic, phosphoric, and boric acids) adjusted to the required $\mathrm{pH}$ using $0.2 \mathrm{~mol} \mathrm{~L}^{-1}$ sodium hydroxide solution. A stock solution of idoxuridine $1 \times 10^{-2} \mathrm{~mol} \mathrm{~L}^{-1}$ (Allergan-Frumtost laboratory) was obtained by direct dissolution of the salt in deionized water (Milli-Q). Poly-L-lysine $(\mathrm{MM}=77300)$ hydrobromide and glutaraldehyde $25 \%$ solution in water were obtained from Sigma.

\subsection{Working Electrode Preparation}

The glassy carbon electrode ( $3 \mathrm{~mm}$ diameter) was polished with alumina $(0.3 \mu \mathrm{m}$, Buehler $)$, and then washed and dried at room temperature. Solutions of the product of the reaction between PLL and glutaraldehyde were prepared using different ratios of the two constituents: PLL ( $1 \% \mathrm{w} / \mathrm{v})$ and glutaraldehyde $(0.05 \% \mathrm{w} / \mathrm{v})$ solutions were used. The reaction appeared to be complete in $10 \mathrm{~min}$. At this stage a $10 \mu \mathrm{L}$ aliquot of the aqueous solution was placed on the polished electrode surface: the tip of the pipette was used to spread the solution evenly over the whole surface. The inverted electrode was then placed in a drying oven at $80^{\circ} \mathrm{C}$ for $2 \mathrm{~min}$. After this drying procedure the electrode was rinsed thoroughly with water and was then immersed in a solution of B-R buffer $\mathrm{pH}$ 5.6.

\subsubsection{General Procedure}

The performance of the modified electrode was tested by two procedures. In the first approach, the voltammograms were recorded after the modified electrode had been immersed in a solution containing idoxuridine and after sufficient time had elapsed (120 s) to accumulate the drug at a controlled potential, and for iodide to be formed. In the second approach, after the iodide had been produced as above, the electrode was transferred to a new buffer solution (previously purged with nitrogen), which did not contain the analyte.

Analyze of dosage forms of iodide in pharmaceutical preparations were carried out using commercial syrups named KI (Teuto Laboratory) and Expec (Legrand Laboratory). An aliquot of these formulations, were diluted with deionized water and transferred directly into the voltammetric cell containing $20 \mathrm{~mL}$ of B-R buffer $\mathrm{pH}$ 2.0. Iodide quantification was done using standard addition method.

\section{Results and Discussion}

\subsection{Oxidation of Iodide on PLL/GA Modified Electrodes}

Typical cyclic voltammograms obtained for the oxidation of $95.6 \mu \mathrm{g} \mathrm{mL}-1$ iodide in B-R buffer $\mathrm{pH} 2$, on bare and modified electrodes were obtained after $10 \mathrm{~s}$ of pre-equilibration and maintained constant during all the experiments and they are shown in Figure 2. Under acidic conditions (pH 2), (Fig. 2, curve a), one anodic peak $\left(I_{\mathrm{a}}\right)$ at $+0.778 \mathrm{~V}$ is seen with the corresponding cathodic peak at $+0.721 \mathrm{~V}$ : these peaks correspond to the transformation of iodide to iodine and vice versa in two electron processes. Previous work has shown that the redox process of $\mathrm{I}^{-} / \mathrm{I}_{2}$ becomes increasingly irreversible as the solution $\mathrm{pH}$ is increased [34]. In the present study cyclic voltammograms of $\mathrm{KI}$ at $\mathrm{pH} 12$ 


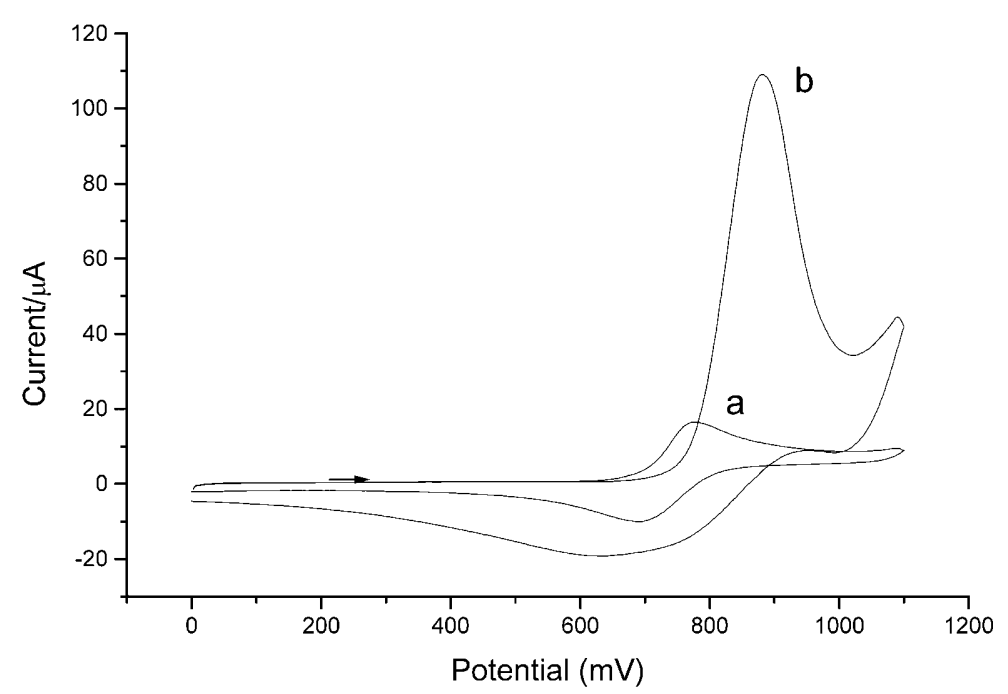

Fig. 2. Cyclic voltammograms for potassium iodide $(95.6 \mu \mathrm{g} \mathrm{mL}-1)$ in B-R buffer $\mathrm{pH}$ 2.0. a) Obtained at a bare glassy carbon electrode. b) Obtained at a PLL/GA modified glassy carbon electrode. $v=100 \mathrm{mV} \mathrm{s}^{-1}$.

showed a well defined oxidation peak at $+0.868 \mathrm{~V}$, but only a small peak is seen in the reverse scan. This is separated by $280 \mathrm{mV}$ from the oxidation peak and values of $i_{\mathrm{pa} / \mathrm{pc}}=0.34$ were found. Linear sweep voltammetry of KI in B-R buffer $\mathrm{pH} 2$ at the glassy carbon electrode showed the oxidation current was linearly dependent on its concentration from 5 to $100 \mu \mathrm{g} \mathrm{mL} \mathrm{mL}^{-1}$, following the equation $i_{\mathrm{p}}(\mu \mathrm{A})=-0.060+$ $0.130 C\left(\mu \mathrm{g} \mathrm{mL}{ }^{-1}\right), r=0.995(n=9)$. The detection limit was calculated to be $1 \mu \mathrm{g} \mathrm{mL} \mathrm{m}^{-1}$.

Figure 2, Curve b, is a cyclic voltammogram obtained for $95.6 \mu \mathrm{gL} \mathrm{m}^{-1}$ solution of iodide at $\mathrm{pH} 2$ on the glassy carbon electrode modified with a PLL: GA film. Iodide gives an anodic peak at about $+0.881 \mathrm{~V}$, for which the height is at least 10 times that obtained at a bare glassy carbon electrode. A relatively small peak was observed in the negative potential sweep direction, indicating the irreversible behavior of iodide oxidation on the PLL film. The effect of $\mathrm{pH}$ on the iodide oxidation peak was investigated from $\mathrm{pH} 2$ to 12 . The peak potential is almost constant at $2<$ $\mathrm{pH}<8$ but is shifted to more positive potentials with further increase in $\mathrm{pH}$. In addition, the peak current $\left(i_{\mathrm{p}}\right)$ is strongly dependant on $\mathrm{pH}$. The currents in acid solution are higher than those obtained in neutral or slightly alkaline solution. In the latter solutions $(\mathrm{pH} \geq 8)$ the peak is extremely small with peak heights similar to those found using the bare $₫$ electrode. Iodide is clearly attracted to the cationic PLL, and as the highest currents were obtained at $\mathrm{pH} 2$, this $\mathrm{pH}$ was used in the following study.

The voltammograms shown in Figure 3 compare the anodic response of the glassy carbon electrode modified by PLL/glut loaded with iodide by (open circuit) immersion in $16.6 \mu \mathrm{g} \mathrm{mL} \mathrm{m}^{-1} \mathrm{KI}$ in B-R buffer $\mathrm{pH} 2$ for $120 \mathrm{~s}$ and by repetitive cycling from 0 to $+1.0 \mathrm{~V}$ (10 cycles). The first linear voltammogram recorded when this coated electrode was transferred to the supporting electrolyte solution (B-R buffer $\mathrm{pH}$ 2.0) after washing it with deionized water was similar to that obtained in the original solution, as shown in
Curve 1 of the inset of Figure 3. On carrying out successive cycling of the electrode potential applied to the electrode, however, the peak current decreased until it was only a fifth the height of the first scan (Curves 2 to 7 of inset of Fig. 3). This was shown later to be owing to the loss of the oxidation product (iodine) from the film rather than poisoning of the film. On the other hand, successive cyclic voltammograms obtained for iodide oxidation directly on the PLL glassy carbon modified electrode immersed continuously in $16.6 \mu \mathrm{g} \mathrm{mL}^{-1}$ solution of KI in B-R pH 2, retained the full current value (Fig. 3B). This behavior indicates that the film was recuperated after cycling in solution containing $\mathrm{KI}$ and can be used to accumulate iodide without any contamina-

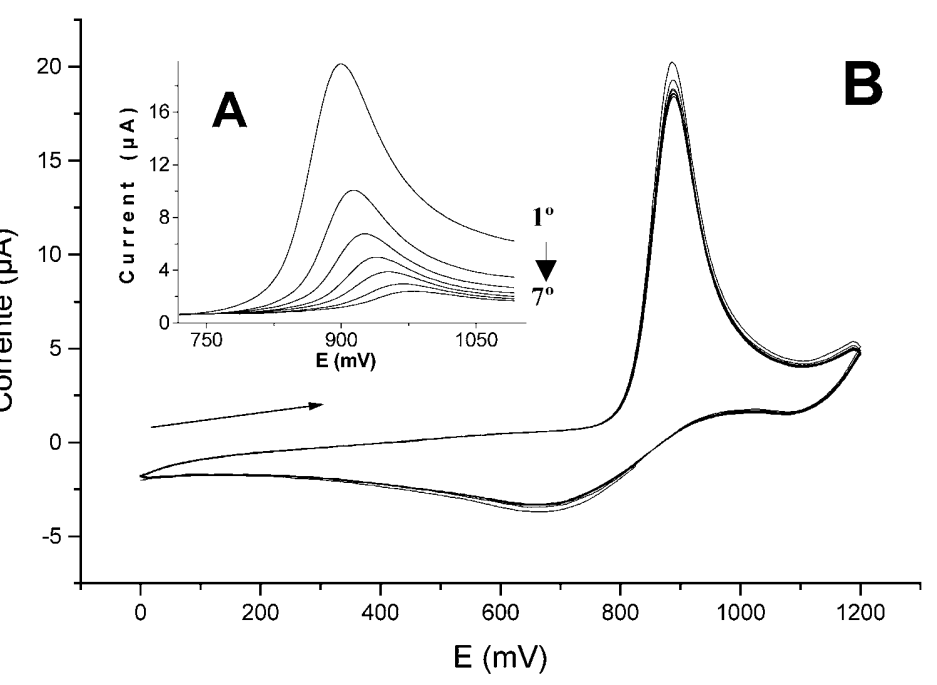

Fig. 3. Repetitive cyclic voltammograms obtained for iodide oxidation on glassy carbon electrode modified by PLL:GA immerse on $16.6 \mu \mathrm{g} \mathrm{mL}^{-1}$ of $\mathrm{KI}$ in B-R buffer $\mathrm{pH} 2$ before (B) and linear scan voltammograms recorded after $120 \mathrm{~s}$ of previous accumulation and subsequent transference to a blank buffer without clean up of the electrode surface. 
tion by the product generated. All further measurements were carried out using the modified electrode directly immersed in the sample containing the analyte.

Crosslinking the PLL involves reaction of some of the amino groups on the PLL with the aldehyde group of the glutaraldehyde to form Schiff Base, and this reduces the number of amino sites available in the film of PLL to bind iodide. The effect of the PLL concentration in the coating solution on the electrode response was investigated, coating the carbon disk with aliquots of $10 \mu \mathrm{L}$ of mixture of PLL (Molecular mass 77300): GA giving the ratios: $50 \%$ : $50 \%$; 75\%: $25 \%$; $95 \%: 5 \%$ and $97.5 \%: 2.5 \%$ (PLL $\%: G A \% ~ m / m$ ). The film was treated as described in the experimental section and the cyclic voltammograms were recorded at the modified electrode in a $16.6 \mu \mathrm{g} \mathrm{mL}-1$ iodide solution in B-R buffer $\mathrm{pH} 2$. The oxidation peak currents obtained with these four electrodes were $2.90 ; 3.45 ; 4.54$ and $8.18 \mu \mathrm{A}$ respectively. This behavior clearly indicates that the lower the extent of crosslinking the greater the binding of iodide and the greater the signal size. The $97.5 \%: 2.5 \%$ PLL: GA coating was selected for use in subsequent experiments. This coating gives acceptable anion exchange properties whilst giving the required improvement of adhesion to the glassy carbon electrode surface. This confirms the findings of our previous study with another analyte [20].

The scan rate dependence of the anodic peak current of the cyclic voltammograms was investigated between 0.01 and $0.2 \mathrm{~V} \mathrm{~s}^{-1}$ using a PLL/GA coated electrode immersed in B-R buffer 2.0 in a solution of $16.6 \mu \mathrm{g} \mathrm{mL}^{-1} \mathrm{KI}$. The anodic peak current increased linearly with the square root of the scan rate for the bare electrode, but at modified electrode with PLL/GA there is a linear relationship from $i_{\mathrm{p}}$ vs. $v$ following the equation: $I_{\mathrm{p}}(\mu \mathrm{A})=i_{\mathrm{p}}(\mu \mathrm{A})=1.08+0.086 v$, $R=0.987, n=12$. This demonstrates that the iodide is oxidized adsorbed on the sites of the modified electrode.
Considerable affinity of protonated amino group on the PLL films for ion-pairing in the presence of iodide can be explained with some aspects discussed in the literature [28, $30,31,35,36]$. The iodide oxidation to iodine on carbon paste electrode modified with protonated organic molecules such as lipophilic agent can involves a synergistic effect of ion-pair formation. The entrapped iodide ions may undergo successive reactions. The iodine can also be accumulated directly via formation of $I_{3}^{-}$, which are again immobilized at the electrode surface according to the ion-pairing principles. Analogous reaction can leads to $\mathrm{I}_{5}^{-}$complex ions.

From the results on the $\mathrm{pH}$ dependence of the peak height, the proton plays an important role to the reaction between the modifier (PLL) and the iodide ions. PLL contains amino group at all $\mathrm{pH}<10$. As a result, the marked effect on peak current at acidic conditions can be attributed to the iodide accumulation on the film, which signal is amplified due simultaneous oxidation of ion pairs formed with iodine.

\subsubsection{Determination of Iodide at the PLL Electrode}

The dependence of the PLL/GA coated glassy carbon electrode response on iodide concentration was investigated from 0.83 to $150 \mu \mathrm{g} \mathrm{mL}^{-1}$, immersing the modified electrode for 10 min directly in a cell containing KI in B-R buffer $\mathrm{pH}$ 2.0. Linear scan voltammograms are shown in Figure 4A. Linear calibration graphs were obtained (Fig. 4B), following the equation

$i_{\mathrm{p}}(\mu \mathrm{A})=1.54+0.962 C\left(\mu \mathrm{g} \mathrm{mL} L^{-1}\right), R=0.998 ;(n=17)$.

The reproducibility of the electrode response was evaluated with a series of 30 repetitive measurements carried out as linear scan voltammograms (at $100 \mathrm{mV} \mathrm{s}^{-1}$ ) recorded for the
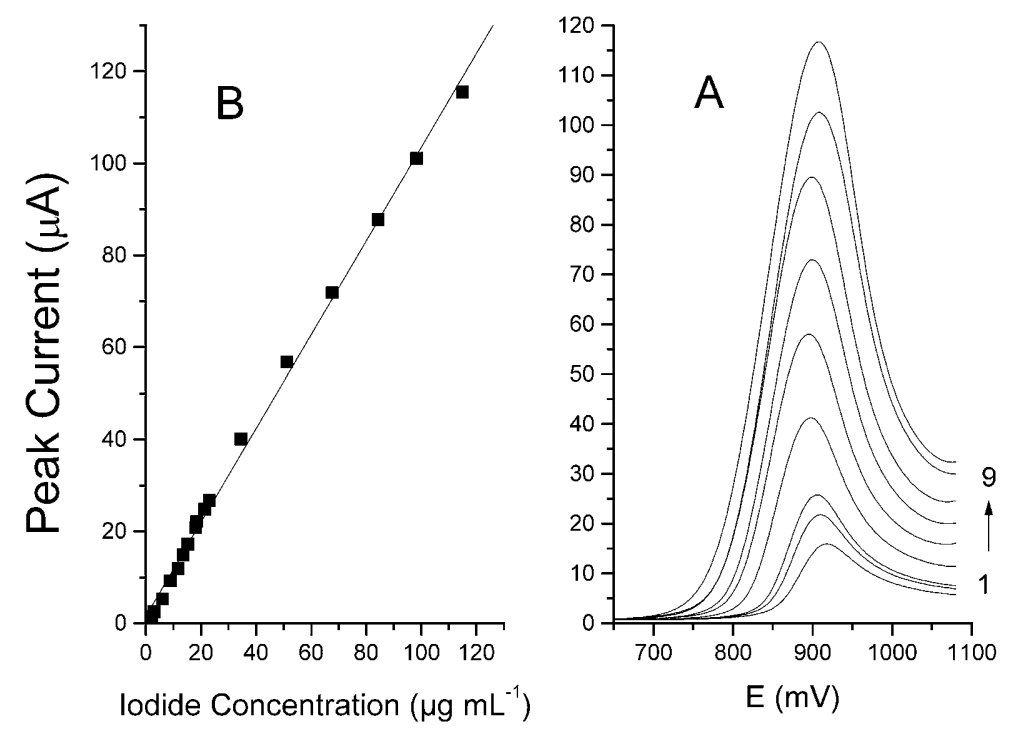

Fig. 4. Linear sweep voltammograms (A) and the corresponding analytical graph (B), obtained for iodide oxidation in B-R buffer pH 2.0 on a PLL/GA modified glassy carbon electrode. Iodide concentration: Curve (1) 11.8 ; (2) 18.4 ; (3) $23.1 ;$ (4) 34.5 ; (5) 51.2 ; (6) 67.7 ; (7) 84.4 ; (8) 98.3 ; (9) $115 \mu \mathrm{g} \mathrm{mL} \mathrm{m}^{-1} \cdot v=100 \mathrm{mV} \mathrm{s}^{-1}$. 
PLL/GA-coated electrode in a $120 \mu \mathrm{g} \mathrm{mL} \mathrm{mL}^{-1} \mathrm{KI}$ in B-R buffer $\mathrm{pH}$ 2.0, using water to wash the electrode surface between each scan. A mean peak current value of $117 \pm$ $3.2 \mu \mathrm{A}$ and relative standard deviation of $2.70 \%$ were obtained. The detection limit ( $3 \mathrm{\sigma} / \mathrm{slope})$ was calculated to be $0.010 \mu \mathrm{g} \mathrm{mL} \mathrm{L}^{-1}$. Thus the oxidation of iodide on PLL films can readily be applied to the determination of iodide at concentrations 100 times less than using a glassy carbon electrode without modification.

The possible interference from various anions and cations were examined. Fluoride, chloride, bromide, perchlorate, sulfate, acetate, $\mathrm{Cu}(\mathrm{II}), \mathrm{Pb}(\mathrm{II}), \mathrm{Cd}$ (II), $\mathrm{Zn}$ (II) ions present in the analyte solution did not interfere with the determination of iodide at a glassy carbon electrode modified with PLL/GA films. Iodate and periodate clearly interfere as they oxidize the iodide.

\subsubsection{Analytical Applications}

The method described was applied to the determination of iodide in two pharmaceutical preparations: These commercial products are named KI (Teuto Laboratory) and Expec (Legrand Laboratory). An aliquot of the test solution prepared as described in the experimental section was diluted to $20 \mathrm{~mL}$ with B-R buffer solution ( $\mathrm{pH} 2.0$ ), and the modified electrode was immersed in it. The corresponding voltammetric curves obtained for Expec before and after standard addition of iodide are shown in Figure 5. Table 1 shows the mean values of the iodide content claimed to be present by the manufacturers, together with those obtained using the proposed method. The concentration of iodide is in accordance with the values given by the manufacturers of the commercial pharmaceutical products.

For comparison, results were obtained also by using a spectrophotometric method [37]: these results are also shown in Table 1. The results obtained show good agreement between the two methods. At a confidence level of $95 \%$ values of $100.6 \pm 0.24 \%$ and $98.0 \pm 0.30 \%$ were obtained for iodide in the commercial samples, respectively.

\subsection{Electrochemical Behavior of Idoxuridine on a Glassy Carbon Electrode Modified with PLL/GA}

Idoxuridine (IDU) is reduced at a glassy carbon electrode at a potential of around $-0.90 \mathrm{~V}$ giving an irreversible peak corresponding to the cleavage of the carbon-iodine bond [12], as had been proved previously for reduction at a mercury electrode. The peak current is at a maximum value

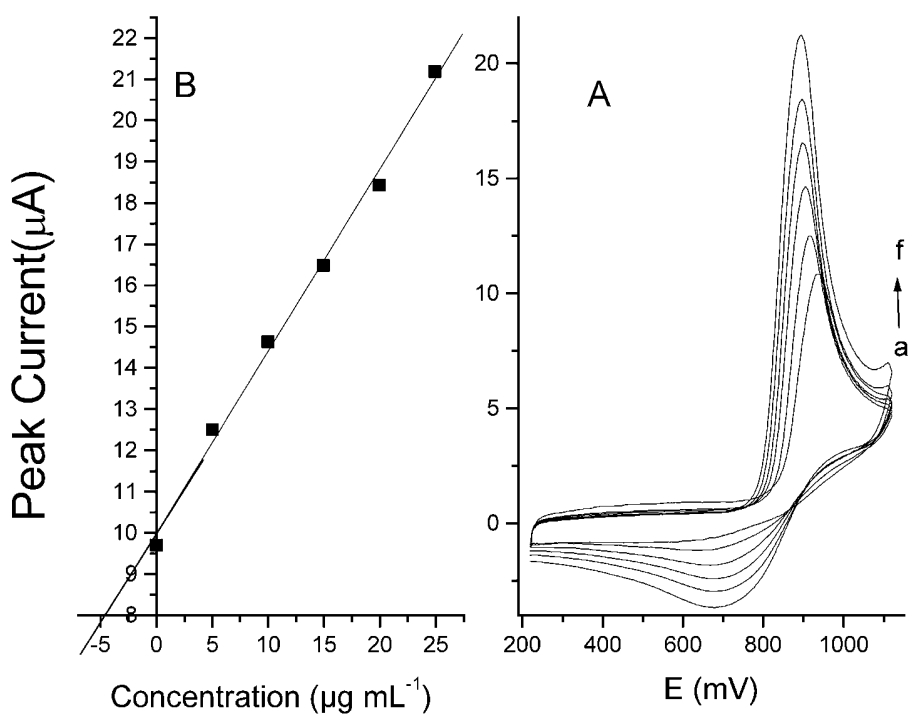

Fig. 5. Standard addition determination of iodide in EXPEC (Legrand Laboratory) Cyclic voltammograms (A) and the corresponding standard additions plot (B). KI Standard additions Curves (b) 4.98; (c) 9.96; (d) 14.9 ; (e) 19.9 ; (f) $24.9 \mu \mathrm{g} \mathrm{mL}-1 . v=$ $100 \mathrm{mV} \mathrm{s}^{-1}$.

at $\mathrm{pH} \leq 5$ and decreases rapidly up to $\mathrm{pH} 7.0$, at which $\mathrm{pH}$ the peak disappears. No oxidation peaks were observed for IDU within the $\mathrm{pH}$ range $2-12$ at a bare glassy carbon electrode.

The reduction of IDU $\left(350 \mu \mathrm{g} \mathrm{mL} \mathrm{m}^{-1}\right)$ on the PLL/GA modified glassy carbon electrode exhibited only a small peak at $-0.9 \mathrm{~V}$ (peak $I_{\mathrm{c}}$ ), as shown Figure 6. This peak decreases further in intensity during subsequent successive scans. Cyclic voltammograms obtained from 0 to $+1.8 \mathrm{~V}$ using the same experimental conditions to did not shown any oxidation signal for IDU. Nevertheless, when the sweep was reversed from $-1.0 \mathrm{~V}$ where IDU is previously reduced, the cyclic voltammograms exhibited a well-defined anodic peak at $+0.87 \mathrm{~V}\left(\right.$ peak $\left.I_{\mathrm{a}}\right)$ on the reverse scan. This increases in height during further cycles (Fig. 6), indicating that the product generated in the previous reduction is pre-concentrated on the electrode surface.

The liberation of halogen from IDU (and other halogenated pyrimidines) is produced by electrochemical reduction [38, 39], photolysis [40], thermal analysis [41], enzymatic action [42] and hydrolysis [43-45]. Thus, the peak at positive potentials observed here can safely be attributed to iodide.

In order to confirm this point, we performed a controlled potential electrolysis for $120 \mathrm{~s}$ at $-0.8 \mathrm{~V}$ on a small volume

Table 1. Determination of iodide in pharmaceutical formulations. Comparison of the developed voltammetric method using a PLL/GA modified electrode with a spectrophotometric method. All values represent the mean of 3 determinations.

\begin{tabular}{llllr}
\hline Dosage form & $\begin{array}{l}\text { Manufacturer's declared } \\
\text { content }\left(\mu \mathrm{g} \mathrm{m}^{-1}\right)\end{array}$ & $\begin{array}{l}\text { Proposed method } \\
\left.(\mu \mathrm{g} \mathrm{mL})^{-1}\right)\end{array}$ & $\begin{array}{l}\text { Spectro-photometric } \\
\text { method [18] }\left(\mu \mathrm{g} \mathrm{mL} \mathrm{m}^{-1}\right)\end{array}$ & $\begin{array}{l}\text { \% Recovery in } \\
\text { proposed method }\end{array}$ \\
\hline KI syrup & 4.98 & $5.01 \pm 0.20$ & $4.99 \pm 1.40$ & $100.6 \pm 0.2$ \\
Expec syrup & 4.98 & $4.88 \pm 0.30$ & $4.97 \pm 0.93$ & $98.0 \pm 0.3$ \\
\hline
\end{tabular}




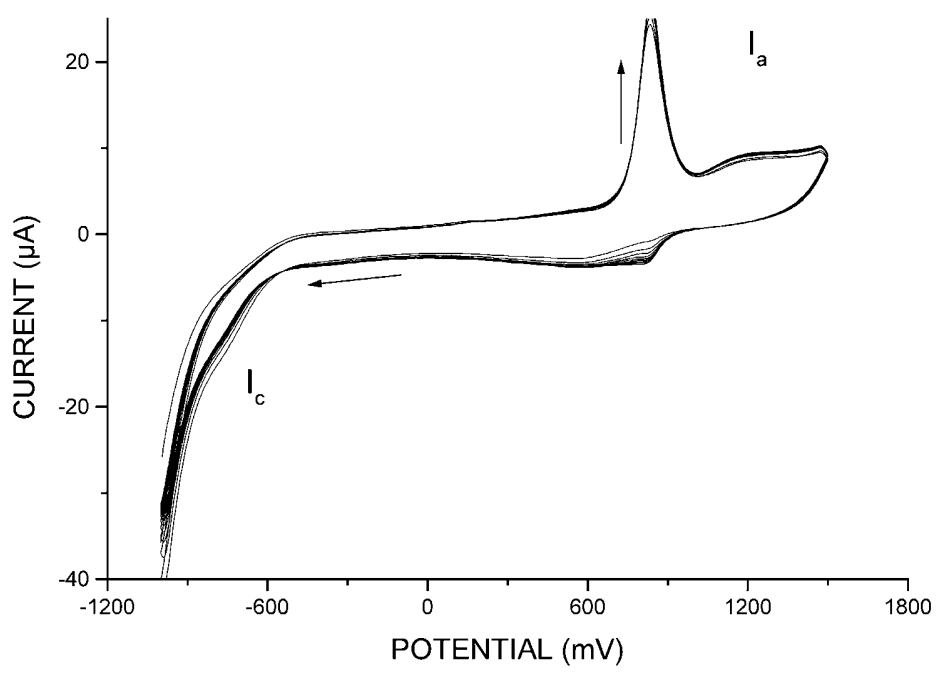

Fig. 6. Cyclic voltammograms of IDU (20 cycles) recorded on glassy carbon electrode for reduction and oxidation of $350 \mu \mathrm{g}$ $\mathrm{mL}^{-1}$ IDU in B-R pH 2,0. $v=100 \mathrm{mV} \mathrm{s}^{-1}$.

of $350 \mu \mathrm{g} \mathrm{mL} \mathrm{mL}^{-1}$ solution of IDU in B-R buffer $\mathrm{pH} 2.0$. Afterwards, cyclic voltammograms were recorded from $0 \mathrm{~V}$ to $+1.50 \mathrm{~V}$ and these showed the well defined peak $\left(I_{\mathrm{a}}\right)$ due to the oxidation of the product generated from reduced IDU at both a bare glassy carbon electrode (Fig. 7A) as a modified electrode with PLL/GA (Fig. 7B). The production of the peak at $+0.83 \mathrm{~V}$ (Fig. 7A) generated after previous electrolysis of IDU on glassy carbon electrode (Curve 1) agrees excellently with the voltammograms obtained for
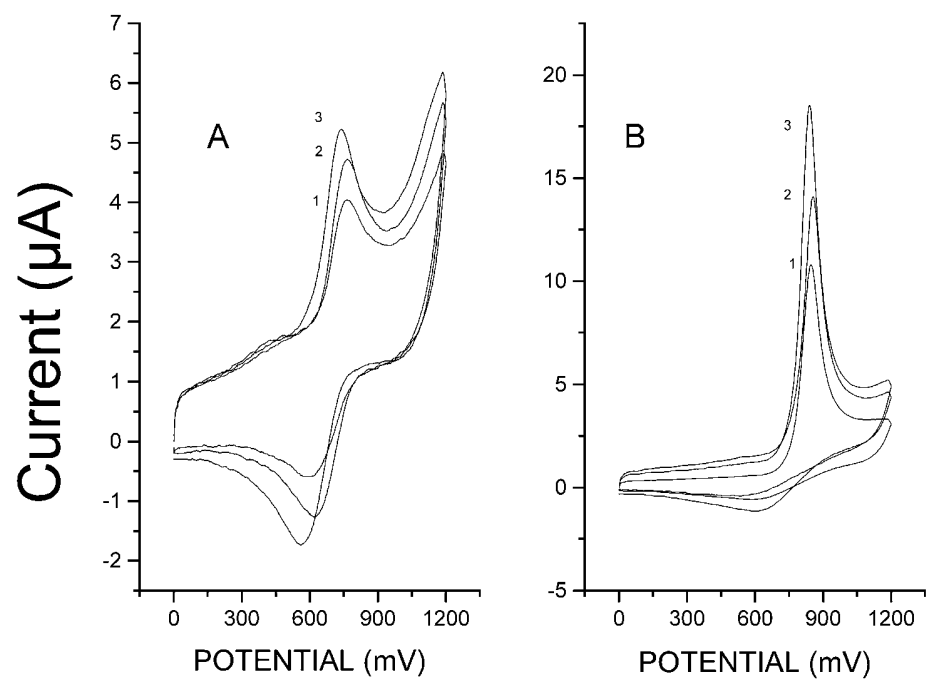

Fig. 7. Cyclic voltammograms obtained for an IDU solution that had been subjected to electrolysis at $-0.8 \mathrm{~V}$ for $120 \mathrm{~s}$. These were obtained on bare and PLL/GA modified glassy carbon electrodes, before (Curve 1) and after (Curves 2, 3) standard additions of iodide. Accumulation time: $120 \mathrm{~s}$. Initial IDU concentration: $350 \mu \mathrm{g} \mathrm{mL}^{-1}$ in B-R pH 2.0 on bare glassy carbon electrode (A) and on a PLL/GA glassy carbon electrode (B). (1) No added iodide (2) after standard addition of $15 \mu \mathrm{g} \mathrm{mL}^{-1}$ of $\mathrm{KI}$ and (3) $30 \mu \mathrm{g} \mathrm{mL}{ }^{-1}$ of KI. $v=100 \mathrm{mV} \mathrm{s}^{-1}$. oxidation of iodide added directly into the cell, which is also shown in Fig. 7A (Curve 2 and 3). Further, the subsequent standard addition of iodide to the electroreduced IDU solution causes successive increases in the peak height proving that free iodide is generated by reduction of idoxuridine. Cyclic voltammograms obtained using the same experimental conditions but using the PLL/GA modified electrode show an even larger peak at $+0.82 \mathrm{~V}$ (Fig. 7B), and this too increases with standard addition of iodide, as shown Figure 7B, Curve 2 and 3.

In order to optimize the conditions for the determination of IDU, via iodide produced during previous reduction of IDU, a systematic study of various experimental parameters including $\mathrm{pH}$, scan rate, deposition potential, deposition time and film composition was investigated.

The effect of deposition potential $\left(E_{\mathrm{dep}}\right)$ and deposition time $\left(t_{\text {dep }}\right)$ on the voltammograms obtained after electrolysis of IDU $\left(35 \mu \mathrm{g} \mathrm{mL}^{-1}\right)$ in B-R buffer $\mathrm{pH} 2.0$ was investigated by monitoring the iodide oxidation using cyclic voltammetry from 0 to $+1.2 \mathrm{~V}$. Controlled reduction of IDU was carried out at potentials from $-0.40 \mathrm{~V}$ to $-1.20 \mathrm{~V}$ for deposition times of 30 to $240 \mathrm{~s}$. The results obtained for deposition potentials of $-0.6 ;-0.7 \mathrm{~V},-0.8 \mathrm{~V}$ and $-1.2 \mathrm{~V}$ are shown in Figure 8 . The oxidation peak is absent at $E_{\text {dep }}$ values less negative than $-0.50 \mathrm{~V}$. At more negative potentials $\left(E_{\mathrm{dep}} \geq\right.$ $-0.60 \mathrm{~V}$ ) the peak height increased rectilinearly with accumulation time between 30 and $240 \mathrm{~s}$. At $E_{\mathrm{dep}} \geq-1.0 \mathrm{~V}$ there is rapid saturation of the film on the electrode. Therefore, a deposition potential of $-0.80 \mathrm{~V}$ was adopted in this study. Figure 8 also shows that the height of the oxidation peak (for $E_{\mathrm{dep}}=-0.80 \mathrm{~V}$ ) increased rectilinearly with accumulation time from 30 to $240 \mathrm{~s}$. Above this time the current reaches a plateau because of saturation of the electrode. A deposition time of $120 \mathrm{~s}$ was chosen as the best

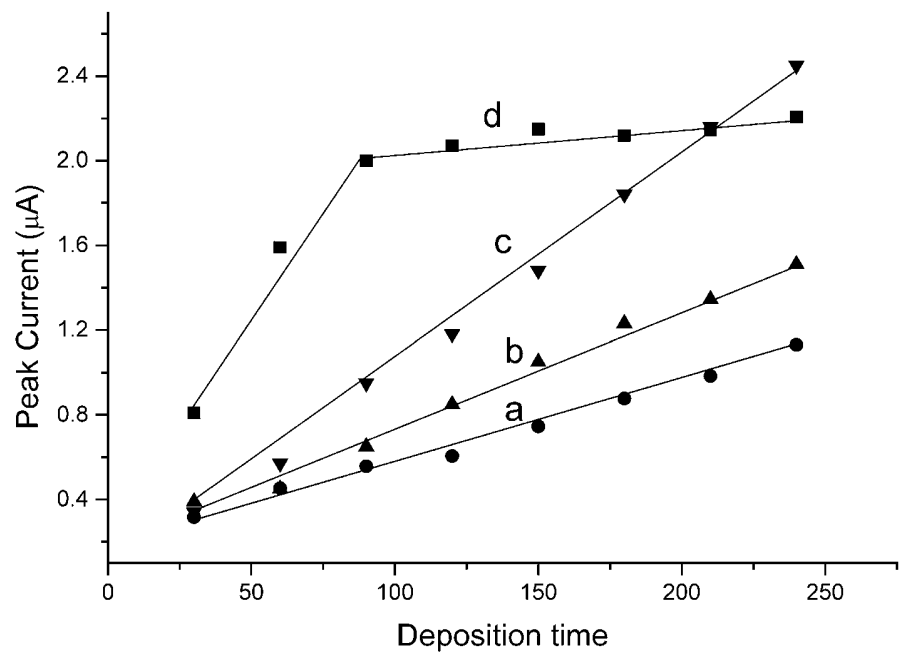

Fig. 8. Effect of deposition potential and deposition time on voltammograms of iodide accumulated by reduction of IDU $\left(35 \mu \mathrm{g} \mathrm{mL} \mathrm{m}^{-1}\right)$ in B-R buffer $\mathrm{pH} 2.0$ on PLL/GA modified glassy carbon electrode. Deposition potential: a). $-0.60 \mathrm{~V}$; b) $-0.70 \mathrm{~V}$; c) $-0.80 \mathrm{~V} ;$ d) $-1.20 \mathrm{~V}$.

(C) 2005 WILEY-VCH Verlag GmbH \& Co. KGaA, Weinheim 
for our present purpose, but longer deposition times could be used to determine lower concentrations of IDU. The peak current obtained for the oxidation of iodide obtained using $175 \mu \mathrm{g} \mathrm{mL}^{-1}$ IDU in B-R buffer $\mathrm{pH}$ 2.0, accumulated at $-0.80 \mathrm{~V}$ for $120 \mathrm{~s}$, increased linearly with scan rate from 10 to $200 \mathrm{mV} \mathrm{s}^{-1}\left[i_{\mathrm{p}}(\mu \mathrm{A})=0.1526+0.1275 v\left(\mathrm{mV} \mathrm{s}^{-1}\right)\right]$, which is to be expected for an adsorption controlled process.

The influence of $\mathrm{pH}$ on the IDU determination was investigated from $2.0 \leq \mathrm{pH} \leq 12$. The peak is at a maximum at $\mathrm{pH} 2.0$, indicating preferential adsorption of the IDU in this solution condition (Fig. 9, Curve 1). The peak current decreased markedly at higher $\mathrm{pH}$ values as shown in Figure 9 (Curve 2) and it is completely suppressed at $\mathrm{pH}>7$. This result indicates that IDU $\left(\mathrm{pK}_{\mathrm{a}}=8.25\right)$ is probably not being reducing at $\mathrm{pH}>7$, as was shown previously on a mercury electrode [12].So, pH 2.0 was chosen as the optimum $\mathrm{pH}$ condition at which to determine IDU.

Using the best experimental conditions (optimized above) an analytical calibration graph was obtained for the IDU determination via iodide oxidation peak obtained from voltammograms recorded after pre-reduction of IDU from $1 \mu \mathrm{g} \mathrm{mL}^{-1}$ to $245 \mu \mathrm{g} \mathrm{mL} \mathrm{m}^{-1}$ at $-0.80 \mathrm{~V}$ for $120 \mathrm{~s}$. The graph is linear and follows the equation: $I_{\mathrm{p}}(\mu \mathrm{A})=-0.290+$ $0.0723 C\left(\mu \mathrm{g} \mathrm{mL}^{-1}\right), R=0.999, N=10$. The reproducibility of the method was determined by making successive measurements on five solutions of $175 \mu \mathrm{g} \mathrm{mL}-1$ at $\mathrm{pH}$ 2.0. A relative standard deviation of $4.2 \%$ was obtained for $n=$ 20. A determination limit of $0.35 \mathrm{~mol} \mathrm{~L}^{-1}$ was calculated using the signal/noise ratio. The same procedure was adopted to construct an analytical curve for IDU using the oxidation of liberated iodide but on a bare glassy carbon electrode. A linear relationship was obtained for IDU concentration from 105 to $350 \mu \mathrm{g} \mathrm{mL} \mathrm{m}^{-1}$, following the

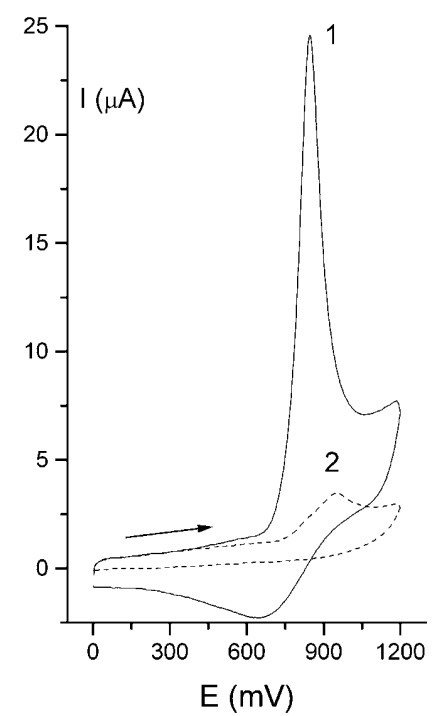

Fig. 9. Effect of $\mathrm{pH}$ on cyclic voltammograms obtained for oxidation of iodide formed from idoxuridine $\left(350 \mu \mathrm{g} \mathrm{mL}^{-1}\right)$ on a PLL/GA modified glassy carbon electrode in B-R buffer at $\mathrm{pH} 2$, 2 (Curve 1) and at pH 5 (Curve 1). Accumulation time: $120 \mathrm{~s}$. Deposition time: $-0.80 \mathrm{~V}$. equation: $I_{\mathrm{p}}(\mu \mathrm{A})=-0.080+4.85 C\left(\mu \mathrm{g} \mathrm{mL} L^{-1}\right), R=0.997$, $n=7$. The corresponding determination limit was $35 \mu \mathrm{g}$ $\mathrm{mL}^{-1}$. The results show that the method using the modified electrode increases markedly the sensitivity relative to that obtained at the bare glassy carbon electrode. The use of the mercury electrode is also less sensitive [12] owing to complications arising from the strong adsorption on mercury.

\subsubsection{Analytical Application}

As a simple test of the general procedure, and in particular to illustrate that it is unnecessary to wash the electrode between determinations, the determination of IDU in a human urine sample was carried out using a PLL/GA modified glassy carbon electrode using a standard additions method. The procedure used was as follows: $1.00 \mathrm{~mL}$ of the urine sample (spiked to be $21 \mu \mathrm{g} \mathrm{mL}^{-1}$ in IDU) was diluted to $10.00 \mathrm{~mL}$ with B-R buffer $\mathrm{pH} 2.0$. The PLL coated electrode was immersed in this solution and cyclic voltammograms were recorded after a pre-electrolysis of IDU at $-0.800 \mathrm{~V}$ for $120 \mathrm{~s}$. The voltammetric peak was recorded and the procedure was repeated three times after additions of iodide. The increase in peak height increased linearly with the concentration of iodide in the urine. The amount of IDU calculated to be in the urine sample indicated a mean recovery of $99.5 \pm 0.4 \%$ with a correlation coefficient of $4 \%$ $(n=5)$. The same methodology was tested for the determination of IDU in the urine sample but using a bare glassy carbon electrode. In this case no signal for the oxidation of iodide was obtained. This result indicates that the PLL/GA coating successfully protects the glassy carbon surface from poisoning by macromolecules in the urine.

\section{Conclusion}

The electrochemical behavior of iodide on a PLL/GA modified glassy electrode shows that such electrodes can be used successful to pre-concentrate iodide. The electrode modification improves the sensitivity and selectivity for iodide determination. An extension of this method has been developed here in which idoxuridine is pre-concentrated by cathodic accumulation as iodide before being determined indirectly as iodide. Other compounds containing $\mathrm{C}-\mathrm{I}$ bonds that can be cleaved by electrochemical reduction should be capable of being determined similarly. The methods for determining iodide and idoxuridine could be used in conjunction to determine them in admixture. The ease and rapidity of electrode preparation gives the methods an interesting advantage over more sophisticated techniques used for these determinations

\section{Acknowledgement}

The authors thank FAPESP, CNPq and CAPES for financial support.

(C) 2005 WILEY-VCH Verlag GmbH \& Co. KGaA, Weinheim 


\section{References}

[1] G. Kleymann, Expert Opinion on Investigational Drugs 2003, 12,165 .

[2] Martindale, The Extra Pharmacoeia, 31st ed., The Royal Pharmaceutical Press, London 1996, pp. 651.

[3] E. DeClercq, J. Descamps, G. Verhelst, R. T. Walker, A. S. Jones, P. F. Torrence, D.Shugar, J. Infect. Dis. 1980, 141, 563.

[4] R. J .Papac, E. M. Jacobs, F. C. Wong, W. Skoog, W. M. Silliphant, Clin. Res. 1961, 9, 79.

[5] P. Calabresi, J. Clin. Invest. 1962, 41, 1484.

[6] C. Robinson, J. Castañer, Drugs Future 1995, 20, 670

[7] M. G. Rimoli, L. Avallone, P. de Caprariis, A. Galeone, F. Forni, M. A. Vandelli, J. Control. Release 1999, 58, 61.

[8] J. A. Williams, X. Yuan, L. E. Dillehay, V. R. Shastri, H. Brem, J. R. Williams, Int. J. Radiation Oncology 1998, 42, 631.

[9] United States Pharmacopoeia, 21st ed., Mack , Easton 1985, 528.

[10] R. E. Garrett, B. P. Chemburger, T. Suzik, Chem. Pharm. Bull. 1965, 13, 1113.

[11] C. M. Riley, J. M. Ault, J. Chromatogr. 1990, 531, 295.

[12] L. G. Chatten, L. Amankwa, Analyst 1985, 110, 1369.

[13] F. C. Anson, J. M. Saveant and K. Shigehara, J. Am. Chem. Soc. 1983, 105, 1096.

[14] F. C. Anson, T. Osaka and J. M. Saveant, J. Phys. Chem. 1983, $87,640$.

[15] A. G. Fogg, R. Pirzad, J. C. Moreira and A. E. Davies, Anal. Proc. Anal. Commun. 1995, 32, 209.

[16] P. Bianco, J. Haladjian and S. G. Derocles, Electroanalysis 1994, 6,67 .

[17] J. Haladjian, I. T. Chef and P. Bianco, Talanta 1996, 43, 1125.

[18] F. Mizutani, S. Yabuki, T. Katsura, Anal. Chim. Acta 1993, 274, 201.

[19] F. Mizutami, S. Yabuki, Y. Hirata, Anal. Chim. Acta 1995 $314,233$.

[20] M. V. B. Zanoni, F. C. Pereira, E. P. Bergamo, N. R. Stradiotto, A. G. Fogg, Electroanlysis 2004, 16, 1439.

[21] J. L. lambert, G. L. Hatch, B. Mosier, Anal. Chem.1975, 47, 915.

[22] C. Reifenhauser, K. G. Heumann, Fresenius J. Anal. Chem.1990, 336, 559.
[23] H. S. Schin, Y. S. Oh-Shin, J. H. kim, J. K. Ryu, J. Chromatogr. A 1996, 732, 327.

[24] E. H. Larsen, M. B. Ludwigsen, J. Anal. At. Spectrom. 1997, $12,435$.

[25] Y. Bichsel, U. von Gunten, Anal. Chem. 1999, 71, 34.

[26] R. Ortiz, O. de Márquees, J. Marques, Anal. Chim. Acta 1996, $215,307$.

[27] R. C. Probst, Anal. Chem. 1977, 49, 1199.

[28] J. Svancara, J. Konvalina, K. Schacl, K. Kalcher, K. Vytras, Electroanalysis 1998, 10, 435.

[29] G. Lu, M. Yang, Q. Zheng, A. Wang, Z. Jin, Electronalysis 1995, 7, 591.

[30] M. K. Kwak, D. S. Park, M. S. Won, Y. B. Shin, Electroanalysis 1996, 8, 689.

[31] J. S. Yeom, M. S. Won, Y. B. Shim, J. Electroanal. Chem. 1999, 16, 463.

[32] K. Kalcher, Electroanal.1985, 321, 666.

[33] A. Walcarius, G. Lefevre, J. P. Papin, G. Renaudin, M. Francois, Electroanalysis 2001, 13, 313.

[34] I. M. Kolthoff, J. Jordan, J. Am. Chem. Soc.1953, 75, 1571.

[35] H.Tang, A. Kinati, M. Shiotani, J. App. Electrochem.1996, 26, 45.

[36] L. G. Wang, X. Wang, A. L. Ottova, H. T. Tien, Electroanalysis 1996, 8, 1020.

[37] I. Iwasaki, S. Utsumi, Ozawa, T., Bull. Chem. Soc. Japan.1953, 26, 108.

[38] W. Adcock, C. I. Clark, A. Houmam, A. R. Krstic, J. M. Saveant, J. Am. Chem. Soc.1996, 61, 2891.

[39] W. Adcock, C. I. Clark, A. Houmam, A. R. Krstic, J. Pinson, J. M. Saveant, D. K. Taylor, J. F. Taylor, J. Am. Chem. Soc.1994, 116, 4653.

[40] R. O. Rahn, Photochem. Photobiol.1992, 56, 9.

[41] P. G. Olafsson, A. M. Bryan, K. Lau, K., J. Chromatogr.1976, 124, 388.

[42] R. Saffhill, W. J. Hume, Chem. Biol. Interact. 1986, 57, 347.

[43] H. W. Barret, R. A. West, J. Am. Chem. Soc.1956, 78, 1912.

[44] J. B. Kortylewicz, J. Adelstein, A. I. Kassis, Sel. Can. Therap.1990, 6,1 .

[45] A. V. Schepdael, N. Ossembe, P. Herdewun, E. Roets, J. Hoogmartens, J. Pharmac. Biomed. Anal. 1993, 11, 345. 